\title{
Preattentive exposure to the thin female beauty ideal does not affect women's mood, selfesteem and eating behaviour
}

Citation for published version (APA):

Jansen, A. T. M., \& de Vries, M. W. (2002). Preattentive exposure to the thin female beauty ideal does not affect women's mood, selfesteem and eating behaviour. European Eating Disorders Review, 10, $208-217$. https://doi.org/10.1002/erv.430

Document status and date:

Published: 01/01/2002

DOI:

10.1002/erv.430

Document Version:

Publisher's PDF, also known as Version of record

Document license:

Taverne

Please check the document version of this publication:

- A submitted manuscript is the version of the article upon submission and before peer-review. There can be important differences between the submitted version and the official published version of record.

People interested in the research are advised to contact the author for the final version of the publication, or visit the DOI to the publisher's website.

- The final author version and the galley proof are versions of the publication after peer review.

- The final published version features the final layout of the paper including the volume, issue and page numbers.

Link to publication

\footnotetext{
General rights rights.

- You may freely distribute the URL identifying the publication in the public portal. please follow below link for the End User Agreement:

www.umlib.nl/taverne-license

Take down policy

If you believe that this document breaches copyright please contact us at:

repository@maastrichtuniversity.nl

providing details and we will investigate your claim.
}

Copyright and moral rights for the publications made accessible in the public portal are retained by the authors and/or other copyright owners and it is a condition of accessing publications that users recognise and abide by the legal requirements associated with these

- Users may download and print one copy of any publication from the public portal for the purpose of private study or research.

- You may not further distribute the material or use it for any profit-making activity or commercial gain

If the publication is distributed under the terms of Article $25 \mathrm{fa}$ of the Dutch Copyright Act, indicated by the "Taverne" license above, 


\title{
Paper
}

\section{Pre-attentive Exposure to the Thin Female Beauty Ideal Does Not Affect Women's Mood, Self-esteem and Eating Behaviour}

\author{
Anita Jansen $^{1 *}$ and Maaike de Vries ${ }^{2}$ \\ ${ }^{1}$ Department of Experimental Psychology, Maastricht University, \\ Maastricht, The Netherlands \\ ${ }^{2}$ University Medical Center St Radboud, Department of Medical \\ Psychology, Nijmegen, The Netherlands
}

Exposure to the thin beauty ideal has been found to decrease women's mood and self-esteem as well as to increase self-reported eating pathology. In the present study, it was tested whether the changes in mood, self-esteem and eating behaviour could be activated outside of conscious attention by ultrashort exposure to either slides of thin media models, obese models or neutral slides. The subliminal exposure did not affect women's mood and self-esteem in the expected way and the eating behaviour of restrained and unrestrained subjects was unaffected by the manipulation. It is concluded that pre-attentive exposure to the thin beauty ideal had no devastating effect on the well-being of women. Note that data from supraliminal studies may be seriously confounded by demand characteristics like answering in a socially desirable way. Copyright (C) 2001 John Wiley \& Sons, Ltd and Eating Disorders Association.

Keywords: eating disorders; restraint; cognition; self-esteem; exposure

\section{INTRODUCTION}

Eating disorders are far more common among women than men and their prevalence is higher in cultures in which a thin female beauty ideal prevails than in cultures without this ideal (e.g. Striegel-Moore, 1995).

*Correspondence to: Professor A. Jansen, Maastricht University, Faculty of Psychology, Department of Experimental Psychology, PO Box 616, 6200 MD Maastricht, the Netherlands. E-mail: a.jansen@psychology.unimaas.nl 
These findings of greater exposure to the thin female beauty ideal being associated with greater levels of disordered eating, led to the widespread idea that the 'perfect figure' culture is the key determinant of body dissatisfaction and eating disorders in women. Although it is hard to demonstrate directly that increasing exposure to the thin ideal figure is related to an increase in the prevalence of eating disorders, there is experimental evidence showing that exposure to thin media models and eating disorder-related symptoms are positively associated with each other (see e.g. Irving, 1990; Stice et al., 1994; Tiggeman and Pickering, 1996; Pinhas et al., 1999).

Until now, the experimental studies on the influence of thin models on the well-being of women used supraliminal exposure to the thinnessideal, meaning that the stimulus materials were consciously noticed and thus favouring controlled or strategic processing of the material. A major problem with these methods and the reliance on self-reports is that they are easily biased by demand characteristics. Moreover, the selfreports probably are not about processes and representations that exist outside awareness. A large series of elegant studies on pre-conscious processes has shown that, although unnoticed, implicit information is able to influence emotions, cognitions and behaviour (Greenwald and Banaji, 1995; Bargh and Chartrand, 1999). Even constructs such as stereotypes, attitudes and self-esteem are found to be-at least partlypre-attentive, meaning that they can be activated outside of conscious attention, for example by subliminal stimulation (Greenwald and Banaji, 1995).

To study these pre-conscious influences and to avoid demand characteristics, female students participating in the present study were given ultra-short exposure to the thin female beauty ideal. In line with earlier findings, it was hypothesized that the pre-attentive exposure is related to a decrease in self-reported mood and self-esteem as well as an increase in eating disorder symptoms. Furthermore it is expected that the subliminal presentation of fat models has a contrast effect and increases women's mood and state self-esteem. Also a significant relationship between restraintness on the one hand and eating disorders-related symptoms after subliminal exposure on the other is expected to be found. Although Ogden and Mundray (1996) did not find a relationship between levels of restrained eating and body dissatisfaction after exposure to thin and fat models, others found that heavier women and women at risk for body image disturbance report more negative self-evaluations after exposure to thin ideal images than normal weight women and women without risk (Henderson-King and Henderson-King, 1997). More specifically, it is predicted that highly restrained eaters are more depressed and show 
lower self-esteem after subliminal presentation of thin models than low restrained eaters.

Finally, although it is widely argued that there is a relationship between media exposure to thin models and eating disorders, the direct influence of thin-ideal exposure on eating behaviour has never been tested. In the present study, subjects participated in a bogus taste test after being exposed to the models. Because the thin ideal exposure is supposed to decrease mood, and a decrease in mood is related to overeating in highly restrained subjects (e.g. Polivy and Herman, 1993), it was hypothesized that exposure to thin models is related to an overeat response of the highly restrained eaters in the laboratory.

\section{METHOD}

\section{Design}

Female students $(n=59)$ were subliminally exposed to either slides of thin media models, obese models or neutral slides. All subjects were run individually. State mood and state self-esteem were measured before and after the slide series. Following the presentation of slides, the subject participated in a bogus taste test and her caloric intake was determined.

\section{Subjects}

Fifty-nine healthy female students volunteered to participate in what they believed to be a perception study on the relationship between visual advertising and taste evaluation of a product.

\section{Measurements}

\section{State self-esteem and state mood}

These were measured on 100-mm Visual Analogue Scales (VASs). Subjects were asked how they felt at the moment, from 0 (very depressed) to 100 (not depressed at all) and from 0 (very selfdissatisfied) to 100 (very self-satisfied).

\section{Food intake}

The amount of calories eaten during the taste test was determined.

\section{Restraint}

The Restraint Scale (RS; Herman and Polivy, 1980), a 10-item self-report scale measuring attempts to restrain food intake and the loss of control over eating behaviour was used. 


\section{Body satisfaction}

Subjects were asked to give a mark between 0 (very negative) and 10 (very positive) for their own physical appearance.

\section{Materials}

Four types of slides were used (thin models, fat models, neutral slides and practice slides), each category containing eight slides. The experimental 'thin' condition consisted of exposure to eight pictures of thin female beauty ideals, i.e. models selected from women's magazines (Elle and Marie-Claire). The models were rated by four independent observers as very representative of the thin female beauty ideal. The 'fat' condition consisted of exposure to eight pictures of extremely fat women, each above $180 \mathrm{~kg}$. The neutral condition was achieved by exposure to neutral stimuli consisting of office equipment such as a stapler, pencil, telephone and so on. The practice set comprised eight slides of fungi which were validated as neutral by the International Affective Picture System (Lang et al., 1995). The practice slides were also used as fillers in the awareness check. A panther print mask was shown directly after each slide to prevent the occurrence of after-images. The slides were projected by two Kodak monitors and the size of the picture on the wall was $115 \times 76 \mathrm{~cm}$.

\section{Procedure}

Subjects were instructed to eat a small meal $2 \mathrm{~h}$ before participation and to refrain from further eating until the experiment. They were all run individually between 11.00 and 17.30 hours and each subject was randomly assigned to one of the conditions.

After entering the laboratory, the procedure was practiced by using the neutral slides. After the subject completed the VASs (mood and selfesteem), she was presented with a slide set (thin, fat or neutral). The eight slides were presented in eight blocks, meaning that $8 \times 8=64$ slides were presented to each subject. Each slide was shown for $15 \mathrm{~ms}$ and the mask was presented for $100 \mathrm{~ms}$. Between slide and mask there was a 15-ms gap.

After the slide presentation, mood and self-esteem were rated again and an awareness check (forced choice recognition task) was carried out. The subject was presented with 16 masked slides and she was requested to say what she saw (office equipment, a human being or a fungus). In case she did not know, she was invited to guess.

After the awareness check, the taste test started. The subject was presented with four plates richly laden with food she preferred 
(high-calorie food, individually chosen) and a cup of water. She was told that two plates were loaded with popular products and that two other plates contained similar products with subtle taste differences. She was instructed to find and rate the subtle taste differences and to eat as much as she liked. Actually, there were no differences between the pairs of food.

The subject was left alone with the food for $15 \mathrm{~min}$. After the experimenter returned, she rated her physical appearance and completed the RS and the knowledge check. Then, her weight and height were measured and she was paid for her participation.

\section{RESULTS}

\section{Awareness check}

The Kolmogorov-Smirnov Goodness of Fit test revealed that the average of $6.4(\mathrm{SD}=2.3)$ correct answers for 16 slides in the forced choice recognition task, was not statistically significant above chance level $(z=0.9$, n.s.). Thus, for most but not all of the 59 subjects the slides were presented below detection treshold. The data of the five subjects scoring in the highest percentile of correct answers (i.e. 10 and 11 correct answers) were not analysed. A one-way ANOVA showed that there were no differences between the conditions in the numbers of correct answers.

\section{Knowledge check}

After the experiment, subjects were asked to give their ideas on the purpose of the study. Three subjects saw through the goal of the experiment and were excluded from the data analysis. Thus, after the manipulation check and knowledge check, 51 subjects remained for analysis.

\section{Subject characteristics}

Mean characteristics of the 51 subjects were: age 19.8 years (range 17-24, $\mathrm{SD}=1.6$ years); Body Mass Index ${ }^{1} 23.01$ (range 18.7-36.1, $\mathrm{SD}=3.1$ ), restraint score 13.2 (range $3-32, \mathrm{SD}=7.3$ ) and body satisfaction 6.7 (range $4-8.5, \mathrm{SD}=0.9$ ).

Hypothesis 1: the subliminal presentation of thin media models decreases the mood and self-esteem of women, whereas the subliminal presentation of fat models increases their mood and self-esteem.

\footnotetext{
${ }^{1}$ Body Mass Index $=\mathrm{BMI}=$ weight in $\mathrm{kg} \backslash($ height in meters $){ }^{2}$
} 
Table 1. Change in mood and self-esteem in all subjects after subliminal exposure to thin models, fat models and neutral slides

\begin{tabular}{lccc}
\hline & Thin models & Fat models & Neutral slides \\
\hline Change in mood & $3.8(10.7)$ & $-1.2(8.6)$ & $3.4(17.1)$ \\
& $n=19$ & $n=13$ & $n=17$ \\
Change in self-esteem & $-3(11.6)$ & $-7.1(14.3)$ & $-3.8(15.1)$ \\
& $n=19$ & $n=15$ & $n=16$ \\
\hline
\end{tabular}

The results are given in Table 1.

First, it was examined whether the subliminal exposure changed mood and self-esteem independent of the condition. For three subjects data on mood or self-esteem were missing. $t$-Test for paired samples showed no mood change $(t(48)=1.3$, n.s.) but self-esteem decreased significantly through the manipulation $(t(49)=2.4, p<0.03)$. Contrary to the expectation, however, $t$-tests for paired samples showed that it was not the thin condition which showed a decrease in self-esteem $(t(18)=0.1$, n.s. $)$. A marginal decrease in the self-esteem of subjects in the fat condition was found $(t(14)=1.9, p=0.07)$. The self-esteem of subjects in the neutral condition did not change $(t(15)=1.0$, n.s.). It is thus concluded that exposure to thin models did not influence women's mood and self-esteem, whereas exposure to fat models tended to lower their self-esteem but not their mood.

Hypothesis 2: highly restrained eaters are more depressed and show lower self-esteem after subliminal presentation of thin models than low restrained eaters.

The results are given in Table 2.

Table 2. Change in mood and self-esteem in highly restrained and low restrained eaters after subliminal exposure to thin models, fat models and neutral slides

\begin{tabular}{lccccc}
\hline & \multicolumn{2}{c}{$\begin{array}{c}\text { Highly restrained } \\
\text { subjects }(\boldsymbol{n}=\mathbf{2 6})\end{array}$} & & \multicolumn{2}{c}{$\begin{array}{c}\text { Low restrained } \\
\text { subjects }(\boldsymbol{n}=\mathbf{2 5})\end{array}$} \\
\cline { 2 - 3 } \cline { 6 - 6 } & Mood & Self-esteem & & Mood & Self-esteem \\
\hline Thin models & $5.3(12.7)$ & $-4.8(13.3)$ & & $2.1(8.5)$ & $-1(9.8)$ \\
& $n=10$ & $n=10$ & & $n=9$ & $n=9$ \\
Fat models & $0.2(5.4)$ & $-3.9(14.8)$ & & $-4.3(14.2)$ & $-12(13.1)$ \\
& $n=9$ & $n=9$ & & $n=4$ & $n=6$ \\
Neutral objects & $4.4(23.6)$ & $-1.7(19.6)$ & & $2.6(12.1)$ & $-5(11.6)$ \\
& $n=7$ & $n=7$ & & $n=10$ & $n=9$ \\
\hline
\end{tabular}


The median restraint score was 14 . No subjects scored between 11 and 14, therefore subjects scoring 11 or lower were considered to be low restrained eaters $(n=24)$, whereas subjects scoring 14 or higher were classified as highly restrained eaters $(n=26)$. A $2 \times 3$ ANCOVA was carried out on the mood and self-esteem post-measures with mood and self-esteem pre-measures as covariates. The main factors were Group (high versus low restraint) and Condition (thin versus fat versus neutral slides). Considering mood, there emerged neither main effects (for Group: $F(1,48)=0.2$, n.s.; for Condition: $F(2,48)=0.7$, n.s.) nor an interaction effect $(F(2,48)=0.8$, n.s.). Again, however, there was a marginal effect on self-esteem. Although there was no main effect for Group $(F(1,49)=1.9$, n.s. $)$ and Condition $(F(2,49)=0.7$, n.s. $)$, the interaction between both was marginally significant $(F(2,49)=2.6$, $p=0.08$ ). Whereas the self-esteem of all subjects increased in the thin condition, the low restrained subjects showed a decrease in self-esteem after being exposed to fat models. Thus, it was found that subliminal presentation of fat models tended to lower the self-esteem of the low restrained eaters in particular, whereas the self-esteem of highly restrained eaters was not influenced by the exposure.

Hypothesis 3: exposure to thin models induces an overeat response in highly restrained eaters.

The results are given in Table 3.

One low restrained eater was considered an outlier because she skewed the data by eating much more than all the other subjects (ninth percentile). After this subject was removed, a $2 \times 3$ ANOVA was carried out on the calorie intake as dependent variable, with Group (high versus low restrained eaters) and Condition (thin versus fat versus neutral slides) as main factors. Neither main effects for Group $(F(1,50)=6.8$, $p=0.12)$ or Condition $(F(2,50)=0.3, \mathrm{n} . \mathrm{s})$, nor an interaction effect $(F(2,50)=0.5, \mathrm{n} . \mathrm{s})$ emerged. Thus, being subliminally exposed to thin or fat models did not influence the eating behaviour of the present sample.

Table 3. Food intake of highly and low restrained eaters after subliminal exposure to thin models, fat models and neutral slides

Food intake (kcal)

\begin{tabular}{lccc}
\cline { 2 - 4 } & Thin models & Fat models & Neutral slides \\
\hline Highly restrained subjects $(n=26)$ & $282(151)$ & $318(113)$ & $262(92)$ \\
& $n=10$ & $n=9$ & $n=7$ \\
Low restrained subjects $(n=24)$ & $213(68)$ & $223(94)$ & $247(119)$ \\
& $n=9$ & $n=5$ & $n=10$ \\
\hline
\end{tabular}




\section{DISCUSSION}

In the present study, it was tested whether subliminal exposure to thin or fat media models influenced women's mood, self-esteem and eating behaviour. Along the lines of studies using supraliminal exposure to thin and fat models, it was expected that the mood and self-esteem of women would decrease after being exposed to thin female models, whereas their mood and self-esteem were expected to increase after exposure to fat female models. The effects were expected to be significantly more pronounced in highly restrained-eating subjects than in low restrained eaters. It was also tested whether the subliminal exposure to thin models triggered overeating in highly restrained eaters.

The subliminal presentation of stimuli in the present experiment gave subjects minimal possibilities for coping strategies, thereby making it impossible to give socially desirable answers or to show other conscious distortions and biases. By eliminating these possibilities, the effect of thin female beauty models on mood and self-esteem disappeared. No changes in self-esteem were found after being exposed to the fat or thin models and also eating behaviour was not influenced by the manipulation. The latter data support the earlier findings of Waller's group. Waller and co-workers also found that the subliminal presentation of specific eating disorder-related cues did not facililtate eating (Waller and Mijatovich, 1998; Meyer and Waller, 2000).

What do the present data mean? The data suggest that when the beauty of a model is not consciously processed, the model has no effect on the mood, self-esteem and eating behaviour of women with either restrained or unrestrained eating behaviour. This means that the automatic processing of thin ideal bodies does not influence the feelings and behaviour of women, which is of interest for several reasons. First, many advertisements using thin beauty female models are not noticed consciously. Considering the data from the present experiment, implicit exposure to thin female beauty ideals will have no devastating effect on the well-being of women. It also cannot be excluded that studies using supraliminal exposure and finding a mood- and self-esteem-lowering effect of thin models, are seriously confounded by socially desirable answers. After all, when relying on self-reports, the occurrence of demand characteristics is a serious risk.

Second, the data have some implications for treatment. Clearly, it does not matter whether subjects walk around in a world dominated by media models and the thin beauty ideal, as long as they are not consciously processing these stimuli. However, at the moment they show controlled or strategic processing of the thin-ideal, a decrease in mood and self-esteem as well as an increase in body dissatisfaction and 
disordered eating behaviour in subjects prone to eating disorders is expected to occur. This line of reasoning implies that treatment should, at least partly, concentrate on interventions that tackle or shape the strategic processing of the thin-ideal stimuli. It thus might be effective to use a cognitive therapy programme which is aimed at challenging dysfunctional beliefs and schemata concerning, amongst other things, the beauty ideal (see e.g. the recent cognitive therapy manual by Cooper et al., 2000).

\section{ACKNOWLEDGEMENTS}

Thanks are expressed to Peter de Jong, Theo van Aerts and Eric Schouten for their technical assistence.

\section{REFERENCES}

Bargh JA, Chartrand TL. 1999. The unbearable automaticity of being. American Psychologist 54: 462-479.

Cooper M, Todd G, Wells A. 2000. Bulimia Nervosa. A Cognitive Therapy Programme for Clients. Jessica Kingsley Publishers: London.

Greenwald AG, Banaji MR. 1995. Implicit social cognition: attitudes, selfesteem, and stereotypes. Psychological Review 102: 4-27.

Henderson-King E, Henderson-King D. 1997. Media effects on women's body esteem: social and individual difference factors. Journal of Applied Social Psychology 27: 399-417.

Herman CP, Polivy J. 1980. Restrained Eating. In Obesity, Stunkard AJ (ed.). Saunders: Philadelphia; 208-225.

Irving L. 1990. Mirror images: effects of the standard of beauty on the self- and body-esteem of women exhibiting varying levels of bulimic symptomatology. Journal of Social and Clinical Psychology 9: 230-242.

Lang PJ, Bradley MM, Cuthbert BN. 1995. International Affective Picture System (IAPS): Technical Manual and Affective Ratings. The Center for Research in Psychophysiology, University of Florida: Gainesville, FL.

Meyer C, Waller G. 2000. Subliminal activation of abandonment- and eatingrelated schemata: relationship with eating disordered attitudes in a non-clinical population. International Journal of Eating Disorders 27: 328-334.

Ogden J, Mundray K. 1996. The effect of the media on body satisfaction: the role of gender and size. European Eating Disorders Review 4: 171-182.

Pinhas L, Toner BB, Ali A, Garfinkel PE, Stuckless N. 1999. The effects of the ideal of female beauty on mood and body satisfaction. International Journal of Eating Disorders 25: 223-226. 
Polivy J, Herman CP. 1993. Etiology of binge eating: psychological mechanisms. In Binge Eating. Nature, Assessment, and Treatment, Fairburn CG, Wilson GT (eds). Guilford: New York; 173-205.

Stice E, Schupak-Neuberg E, Shaw HE, Stein RI. 1994. Relation of media exposure to eating disorder symptomatology: an examination of mediating mechanisms. Journal of Abnormal Psychology 103: 836-840.

Striegel-Moore RH. 1995. A feminist perspective on the etiology of eating disorders. In Eating Disorders and Obesity. A Comprehensive Handbook, Brownoll KD, Fairburn CG (eds). Guilford Press: New York; 224-229.

Tiggeman M, Pickering AS. 1996. Role of television in adolescent women's body dissatisfaction and drive for thinness. International Journal of Eating Disorders 20: 199-203.

Waller G, Mijatovich S. 1998. Preconscious processing of threat cues: impact on eating among women with unhealthy eating attitudes. International Journal of Eating Disorders 24: 83-89. 